\title{
ВНЕДРЕНИЕ ЭЛЕКТРОННОГО МЕНЕДЖМЕНТА В ПРАКТИКУ ОБРАЗОВАНИЯ
}

\author{
Худайназар Х. Курбанов, \\ Институт педагогических инноваций, переподготовки и повыщения квалификации \\ руководящих и педагогических кадров профессионального образования при Министерстве \\ высшего и среднего специильного образования Республики Узбекистан, Узбекистан
}

Феруза М. Рашидова,

Академический лищей Узбекского государственного университета мировых языков, Узбекистан

DOI: https://doi.org/10.31435/rsglobal_ijitss/30122019/6857

\section{ARTICLE INFO \\ Received 27 October 2019 Accepted 19 December 2019 \\ Published 30 December 2019 \\ KEYWORDS \\ education, digitalization, digital technologies, information management information system, professional competence, monitoring of performance assessment, quality of education, key performance indicators (KPIs).} \begin{abstract}
The article discusses the actual problems of education - digitalization and the development of electronic management in educational institutions; an information system for collecting data on graduates and their occupation; automation of conducting profiles of teachers and the development of their professional competence; monitoring the academic performance assessment; ensuring transparency and improving the quality of education; implementation of a key performance indicators (KPI).
\end{abstract}

Citation: Худайназар Х. Курбанов, Феруза М. Рашидова. (2019) Vnedrenie Elektronnogo Menedzhmenta v Praktiku Obrazovaniya. International Journal of Innovative Technologies in Social Science. 9(21). doi: $10.31435 /$ rsglobal_ijitss/30122019/6857

Copyright: (C) 2019 Худайназар Х. Курбанов, Феруза М. Рашидова. This is an open-access article distributed under the terms of the Creative Commons Attribution License (CC BY). The use, distribution or reproduction in other forums is permitted, provided the original author(s) or licensor are credited and that the original publication in this journal is cited, in accordance with accepted academic practice. No use, distribution or reproduction is permitted which does not comply with these terms.

В настоящее время в ряде стран, в том числе в Узбекистане назрела необходимость решения ряда социально-экономических и экологических проблем, вызванных ускорением глобализации и быстрым ростом технологизации различных сфер, включая образование. В контексте сказанного, перед управлением системой образования возникает потребность в существенном пересмотре ряда вопросов, возникающих в связи наличием вышеуказанных проблем. Сложившаяся интенсификация развития производственных и хозяйственных сфер намного опережает темпы развития образования, призванного обеспечить общеобразовательную и профессиональную подготовку к вновь возникаемым профессиям, учитывая при этом исчезновение ранее функционирующих специальностей.

Современные дети, вступающие в образовательный процесс в предстоящие десятилетия, будут молодыми людьми через 10-15 лет, которые начнут трудовую деятельность, осваивая новые, ныне не практикуемые профессии и специальности. Они вынуждены будут быстро перестраиваться или адаптироваться к новым вызовам будущего. В контексте этого, современное поколение требуется обучать в духе толерантности, прозрачности, объективности, 
чтобы создавать условия социальной активности с раннего возраста в условиях творческой атмосферы, широкого мировоззрения, обогащения интеллектуального потенциала, с тем, чтобы они были толерантными активными гражданами, адаптирующимися к вызовам современности, решали в команде, вопросы конструктивно, компетентно и профессионально.

В Постановлении Президента РУз от 5 июня 2018 года «О дополнительных мерах по повышению качества образования в высших образовательных учреждениях и обеспечению их активного участия в осуществляемых в стране широкомасштабных реформах» отмечено, что за последние годы в стране принимаются широкомасштабные меры по созданию системы высшего образования, соответствующей приоритетным направлениям социальноэкономического развития и требованиям международных стандартов [1].

Вместе с тем, в Постановлении подчеркнуто, что «Сохраняется ряд проблем, препятствующих повышению качества образования в высших образовательных учреждениях, обеспечению активного участия данных учреждений в осуществляемых в республике широкомасштабных реформах, преобразованиях в социальной и экономической сферах», в частности, несоответствие системы оценивания обучающихся современным требованиям; отсутствие современной системы оценки деятельности педагогов; трудности определения способности абитуриентов к логическому мышлению; отсутствие эффективного общественного контроля за образовательным процессом; неудовлетворительное участие и недостаточная инициативность высших образовательных учреждений; отсутствие инновации по обмену мнениями и анализу состояния образования, по системному изучению, анализу и внесению предложений по решению имеющихся проблем и недостатков в соответствующих сферах.

Эффективное решение всех этих вопросов можно последовательно решать путем реализации поставленных в Постановлении задач, в том числе путем внедрения цифровых технологий в деятельность каждого образовательного учреждения, подключаясь поэтапно к общей платформе электронного менеджмента, который начал успешно внедряться в нашей республике.

В своем обращении к Парламенту Президент Республики Узбекистан Ш.М. Мирзиёев затронул вопрос разработки Национальной концепции цифровой экономики, предусматривающей обновление всех секторов экономики на цифровых технологиях, и реализацию программы «Цифровой Узбекистан - 2030» [2]. Внедрение цифровых технологий во всех отраслях, реформы и передовые технологии, конечно, не могут обходиться без образования. Кадровое обеспечение и образование является основой цифровой экономики. Следует отметить, что будущее цифрового Узбекистана в руках наших молодежи и профессионалов.

Цифровизация - процесс кодирования различных показателей системы образования, который позволяет автоматизировать определенные функции и деятельность системы управления [3]. Такой подход показывает положительные результаты в ходе внедрения Информационной системы управления образованием (англ. EMIS - Education Management Information System), начатой Министерством дошкольного образования Узбекистана и Министерством высшего и среднего специального образования.

Следует отметить, что на сегодняшний день в республике в сфере управления образованием не существует единой, интегрированной системы управления. Есть разрозненные системы и базы данных учеников и преподавателей, выполняющие функции контроля и надзора. Не внедрена система отслеживания ключевых показателей эффективности (КПЭ). Отсутствует автоматизированная система сбора данных о выпускниках и их роде деятельности, профили преподавателей, автоматизация учебного процесса производится только некоторыми ВУЗами республики.

Информационная система управления образованием позволяет осуществлять цифровизацию образования, развитие цифровых библиотек и цифрового книгоиздания, которое является приоритетной государственной политикой, немыслимая без достижения цифровой грамотности обучаемых и обучающих.

Вместе с тем следует отметить, к сожалению в деятельности ныне действующих академических лицеях уделяется недостаточное внимание вопросам подготовки интеллектуально развитой молодежи путем реализации образовательной и воспитательной работы, обеспечения электронного менеджмента в образовании, проведения мониторинга оценки эффективности деятельности участников образовательно-воспитательного процесса, проведения оценки уровня знаний учащиеся, что не позволяет обеспечить требуемый уровень качества образования. 
В соответствии с Постановлением Президента Республики Узбекистан от 14 марта 2017 года принята Программа мер по дальнейшему повышению эффективности учебного процесса и повышению показателей поступления выпускников академических лицеев в высшие образовательные учреждения, предусматривающей «кардинальное улучшение качества образования, широкое внедрение прогрессивных педагогических и информационнокоммуникационных технологий, электронных образовательных ресурсов и мультимедийных обучающих систем, способствующей раскрытию и активизации творческого потенциала учащихся, формирующей и развивающей навыки самостоятельной деятельности в процессе получения знаний с учетом индивидуальных особенностей каждого учащегося; разработки и утверждение комплекса мер по повышению профессионального и педагогического мастерства преподавателей академических лицеев и поощрения их деятельности путем проведения тренингов, семинаров, в том числе по основам применения информационно-коммуникационных технологий, иностранных языков в образовательном процессе» [4].

С учетом изложенного, внедрение информационной системы управления образованием позволит своевременно проанализировать успешность выполнения требований государственного образовательного стандарта, активного, целенаправленного использования информационнокоммуникативных технологий обучающими и обучающимися, повысить результативность качества образования, создать эффективную систему мониторинга повышения квалификации специалистов, расширить доступность к различным формам обучения, обеспечить прозрачность образования, управлять эффективностью образовательной системы, включая, развитие потенциала административно-руководящего состава образовательного учреждения.

Главным мотивом деятельности по совершенствованию системы EMIS является понимание значимости испрашиваемых данных. Опыт разных стран выявил главные трудности в обеспечении постоянной институциональной поддержки и убеждении основных заинтересованных сторон в необходимости использования полученных данных. Неудачные попытки в некоторых странах были связаны с тем, что слишком много внимания уделялось сбору и публикации данных без учета того, кто будет ими пользоваться и с какой целью. Система EMIS должна быть тесно связана с работой специального подразделения или группы лиц, принимающих ответственные решения, которые ясно излагали бы свои потребности в той или иной информации, а также возможности ее использования [5].

С учетом международного опыта, внедрение информационной системы управления образованием в образовательном учреждении республики предполагает реализацию следующих мероприятий:

ситуационный анализ, с выбором наиболее оптимального метода создания базы данных для внедрения единой информационной системы управления образованием;

разработка системы отслеживания ключевых показателей эффективности;

создание команды для разработки программного обеспечения «Единая информационная система управления образованием» со свойством интеграции в единую систему электронного правительства (e-gov);

поэтапное пилотирование разработанной системы;

сбор откликов и рекомендаций, анализ ошибок/комментариев и улучшение системы;

обучение персонала, административного состава к работе с программой.

Как выясняется управление самыми динамическими данными внутри образовательного учреждения регулируются на основе менеджмента первичных базы данных, которое должно быть обновляться регулярно, что облегчает ежедневные составления таблиц, объединения их в единую базу, включая разно системных данных, которых мы легко привыкли делать на Exel. При условии, если все образовательные учреждения подключатся в эту систему управления школьной информацией, большие и малые, частные и государственные это расширит возможности и упростить процесс управления, которая позволит комплексную систему управления образовательной информацией, отвечающих потребностям всех типов школ. Эта система создана для получения картины эффективности каждого образовательного учреждения в целом в стране, которое является одним из индикаторов установления прозрачности системы образования в целом.

Система оценки качества образования строится на сочетании таких оценочных механизмов, как внешняя и внутренняя оценка качества образовательного процесса и его результатов, обратной связи различных участников образовательных отношений о качестве 
образовательных услуг, которые являются непосредственными индикаторами системы электронного менеджмента [6].

С начала 2018 года академическим лицеем УзГУМЯ начато пилотирование проекта по электронному менеджменту в образовательном учреждении с целью получения объективной оценки состояния успеваемости всех учащихся академического лицея, деятельности обучающих и обучаемых, направленную на улучшение успеваемости учащихся и создание условий, обеспечивающих реализацию проблемы улучшения качества образования.

Нами проводятся исследования на базе академического лицея, направленных на внедрение электронного менеджмента, маркетинга и мониторинга системы образования, предусматривающие:

- обеспечение реализации системы мониторинга академической успеваемости каждого обучаемого - система SRS (Student's Record System), связанной со статистическими данными, полученными в ходе проведенных экспериментальных исследований, представляющих возможность апробации, валидации и внедрения в процесс образования;

- создание потенциальной базы данных педагогов - TRS (Teachers' Record System), которые будут основываться на результатах обучаемого (т.e. «Student's results”);

- обеспечение объективной системы оценивания (Transparent Assessment system) основных предметов;

- внедрение инновационных процессов в академических лицеях становится национальным бизнес продуктом, который позволяет импортировать и экспортировать менеджмент в образовании в другие образовательные учреждения.

Как отмечено в Стратегии действий по пяти приоритетным направлениям развития Республики Узбекистан в 2017-2021 годах для достижения повсеместного внедрения информационно-коммуникационных технологий в экономику, социальную сферу, системы управления необходимо постоянное совершенствование компетенции менеджеров, педагогов, включая специалистов по ИКТ в системе образования по принципу образования в течение жизни [7, 8, 9].

Таким образом, электронный менеджмент в образовании позволяет своевременно проанализировать успешность выполнения требований Узбекского государственного стандарта (УзГОС), активного, целенаправленного использования ИКТ (информационной коммуникативной технологии) обучающими и обучающимися, повысить результативность качества образования, повышения квалификации, доступность разных форм обучения, обеспечить прозрачность образования, эффективность образовательной системы, развивать компетентность педагогов, включая, административный состав образовательного учреждения.

\section{ЛИТЕРАТУРА}

1. О дополнительных мерах по повышению качества образования в высших образовательных учреждениях и обеспечению их активного участия в осуществляемых в стране широкомасштабных реформах. Постановление Президента РУз, 05.06.2018 г. [Электронный ресурс]. - Режим доступа: http://www.lex.uz/ru/pdfs/3765584, свободный.

2. Послание Президента Республики Узбекистан Шавката Мирзиёева Олий Мажлису. [Электронный peсурс]. - Режим доступа: http://uza.uz/ru/politics/poslanie-prezidenta-respubliki-uzbekistan-shavkatamirziyeevas-28-12-2018, свободный.

3. Клячко Т. Цифровизация образования - надежды и риски. / Вести образования. Февраль, 2018. [Электронный ресурс]. - Режим доступа: https://vogazeta.ru/articles/2018/2/26/blog/2148tsifrovizatsiya_obrazovaniya_nadezhdy_i_riski, свободный.

4. О мерах по дальнейшему совершенствованию деятельности образовательных учреждений среднего специального, профессионального образования. Постановление Президента Республики Узбекистан от 14.03.2017 №ПП-2829. [Электронный ресурс]. - Режим доступа: http://lex.uz/docs/3133117, свободный.

5. Всемирный доклад по мониторингу ОДБ. Образование для всех к 2015 году Добьемся ли мы успеха? [Электронный ресурс]. - Режим доступа: https://unesdoc.unesco.org/ark:/48223/pf0000154743_rus, свободный.

6. Ф.М.Рашидова. CEFR=ГОС РУз: Проблемы, решение, внедрение. Методическое пособие. Ташкент, 2018. - 50 с.

7. О стратегии действий по дальнейшему развитию Республики Узбекистан. Указ Президента Республики Узбекистан. УП-4947 от 07.02.2017 г. [Электронный ресурс]. - Режим доступа: http://www.lex.uz/ru/docs/3107042, свободный.

8. Рашидова Ф. Системная роль информационно-коммуникативных технологий (ИКТ) в комплексной реализации процесса овладения иностранным языком // Педагогические Науки. - Москва. - 2013. -№5. - С. 17-22.

9. Инчхонская декларация и ЦУР 4 - Образование-2030: Рамочная программа действий. [электронный pecyрс] - Режим доступа: http://unesdoc.unesco.org/images/0024/002456/245656R.pdf, свободный. - Стр.30. 